\title{
A Dimensão Simbólica nas Organizações: Fragmentos de um estudo com idosos
}

Altair Macedo Lahud Loureiro *

$\overline{1}$ ste texto contém, tão somente, o resultado de um processo de reflexão, estudo e pesquisa de quem se renova em cada oportunidade de pensar em conjunto, na interação interpessoal com alunos, ouvintes, participantes (ou leitores) .

É sempre uma situação crítica o que resulta desse complexo fato, que pode gerar complexa emoção e reações díspares, nos díspares "parceiros"; mas é também um desafio! Avoluma minha preocupação a especificidade do conteúdo, que este escrito apresenta: um ângulo outro, ou mais, ou apenas uma das dimensões do processo organizacional - a dimensão simbólica - não tão, ou quase nada, ou mesmo nada, considerada nesse newtoniano esquema capitalista e positivista, tão em voga, na visão clássica, redutora, simplificadora e cartesiana do mundo ocidental atual. Apesar dessa sensação, misto de satisfação e angústia, parafraseando Edgard Morin, digo que "a consciência da incerteza, da eventualidade... está longe de me ter conduzido ao desespero. Ao contrário é estimulante trocar a certeza mental peló risco, já que, assim se ganha a chance. As verdades... da complexidade, e serei compreendida por aqueles que, como eu, se asfixiam no pensamento fechado, na ciência fechada, nas verdades limitadas, amputadas, arrogantes. É estimulante, enfim, considerar o mundo, a vida, o homem, o conhecimento, a ação, como sistemas abertos" (Morin, 1979) A idéia de homem como sistema fechado desapareceu; o que existe é a emergência de possíveis sistemas auto-organizadores (Atlan, 1992).

O pensamento - já sem ser só meu, impregnado de idéias outras, de outros estudiosos, que noutros tempos/momentos pensaram e produziram os conceitos que agora, nesta reflexão registrada, retomo, numa simbiose "ladra", fazendo-os meus, com a audácia entusiasmada de "mestre", não mais que eterno aprendiz - cresce e leva-me, corajosamente apoiada na incerteza sobre tudo, apresentar um pouco de pesquisa, que realizei sobre apenas um tópico da gestão escolar/educacional/cultural: a organização. Desta feita, nessa busca, minha preocupação foi com a dimensão simbólica nas organizações e, considerando a possibilidade de uma mais aberta visão de mundo, filtrar o processo e propor, conjuntamente com os professores aposentados pertencentes ao grupo analisado, uma dinâmica organizacional um processo em ação.

De forma sintética esta característica humana, ao lado de todas as outras, mesmo das menos consideradas, aquelas que existem, mas desprezadas a priori, podem conter em si as condições para uma nova consideração, não ortodoxa, talvez, quem sabe, até tida (esta atitude de envolvimento delas) como uma heresia. Não só os dados quantificáveis, mas também o afetivo, a emoção, as "franjas turbilhonares" - porque nas pontas, nas "barras", presas aos limites como um crochet, mas que não entram na medida da "peça", mas plenas de vida, dinâmicas - agitadas, mas contidas, é o considerado.

Dentro desta ótica, é que desenvolvi a pesquisa sobre uma possível reparadigmatização, e que penso, em apresentando seus resultados, e encaminhados ao total conhecimento da mesma, estar contribuindo nas discussões sobre a Administração da Educação, sobre "Qualidade e Gestão", no sentido de que seja pensado ou percebido, 
se ainda não foi, que, além das normas e regras, é preciso "pensar o impensado que subjaz as estrutura de pensamento", considerar também o até desconhecido: afetivo. Lembrar que o "ideal organiza o real" e ver no homem a sua incompletude característica (Carvalho, 1990). A preocupação é também romper rumos da academia e tentar a mudança numa ótica mais larga, a transformação que pressente, mas que custa a se realizar ou se aceitar. Estamos envolvidos, submersos, encharcados na "visão de mundo" do lucro, da produção, do igual parametrizado que não pode perder tempo com o desigual, o diferente,: a alteridade. Daí a preocupação em buscar a profundeza das imagens expressadas nos símbolos.

$\mathrm{O}$ que foi a pesquisa?

Parti de reflexões sobre processo organizacional tradicional e avancei para o diferente, para a mudança dessa ação. Comecei então por pensar 0 fenômeno organizacional numa outra visão.

A complexificação, decorrida de vários fatores, nas relações dos homens entre si, com a natureza e os demais, nas várias culturas, obrigou-os a se posicionarem, ora mais distantes, ora mais próximos uns dos outros, de forma dinâmica, num movimento caleidoscópio, apresentando desenhos multiformes, sombreados nas nuanças diferenciadas que, de qualquer maneira, como numa "Guernica" improvisada, exigem um arranjo, a montagem, o acabamento, a completação ou aperfeiçoamento ao qual se deu o nome de organização.

A idéia de organismo funcionante, gerador de algo - produtor - precisava ser considerada na confusão das partes. Mas as partes nem sempre foram todas consideradas, nas suas características e diferenças, ou melhor: algumas até foram utilizadas no quebra-cabeça montado a todo custo, como engrenagens acopláveis no mosaico previsto, preconcebido na visão unificada de alguém, ou de alguns que, com força de coerção, dita coesạ̃o, por vezes esqueceram deliberadamente as partes diferentes; deixaram de lado não apenas pedaços de pensamentos divergente, enfoques outros,- mas, o que é mais sério, deixaram fora, "excluidos", homens ou grupos de homens com para outro - a audácia de serem diferentes, de terem o "pecado" da desigualdade. A. ausência neles dos recortes, saliências e reentrâncias necessárias à formatação do mapa esperado pela geo- grafia preestabelecida, relegou a segundo, terceiro... último plano, até a desconsideração total, as suas vozes/presenças no coral afinado pelo poder instituído. Isto os fez estigmatizados, marginalizados, e seus pensamentos não foram somados, quiçá ouvidos. No afã de conciliar as igualdades, no nivelamento das arestas aparadas, podadas pelas regras, pelo agir sensualmente, esteriotipante da maioria, os homens foram organizados; a organização passou colocar em "ordem unida" os pobres mortais.

Isto posto, poder-se-ia perguntar: seria a organização então algo exterior ao homem, construído por outros homens, mais fortes, no poder, apenas para amarrar a humanidade, controlando os surtos de desarmonia nas sociedades, especialmente na sociedade capitalista? Como considerar a diversidade na unidade?

A organizaçã é algo inerente à natureza humana e é interior, na sua possibilidade de autoorganização, como reequilíbrio constante, como geradora de condição impeditiva da teimosa harmonia destruidora, mortífera para o crescimento da inovação. $O$ homem tem a capacidade de mudar, introjetando os desequilíbrios e rupturas no sedimentado comportamento, o que faz dele um ser que se auto-organiza. Mas é preciso romper a argamassa do preestabelecido, em si mesmo, para mudar. Assim sendo, como conhecer esta capacidade e sua estrutura? Como desvendar o interior ativo do ser humano, o seu imaginário?

Numa visão diferente da forma clássica de organização - numa perspectiva alternativa, e de alteridade, considerando o ser humano na sua imaginação - prestigiando a multiplicidade dos aspectos, sem esquecer o único, a pesquisa, na sua operacionalização, escolhe o professor na sua idade avançada, na velhice, já aposentado, com suas imagens do tempo, da angústia do passar mesmo e a maneira de dominar esse tempo para, refletindo sobre os fenômenos do envelhecimento e da morte, sem esquecer a diversidade de mentalidade nas culturas, bem como a noção de tempo, sugerir vetores para um possível diferente processo de organizar.(Lahud, 1990) Levanta e analisa imagens simbólicas do grupo, através do teste A.T-9 - Arquétipo Teste de Nove Elementos criado por Yves Durand, ampliando seus resultados com simbologia e resultados de estudos sobre o fenômeno da morte. (Durand, 1988) 
O trabalho se encerra numa proposta profunda do grupo: um trabalho se fazendo. Aborda a teoria do imaginário (Durand, 1989), que inclui, entre suas funções, a tarefa de tentar dominar a angústia temporal, o teste A.T-9, o paradigma holonômico (Carvalho, 1990) - pércepção de mundo que precavê a organizacionalidade da institucionalização - apesar de nelas buscar princípios possíveis, para não "reinventar a roda", no confronto com pretensão antropolítica de organização - organização que prestigia a dimensão simbólica ao lado de outras dimensões, já conhecidas, e sua relação com o fazer organizacional.

A pesquisa desvendou imagens do grupo e descobriu sua paisagem mental, o que possibilita o apontamento de pistas para a organização diferente (Barros, 1991).

O que pretendi com a pesquisa?

Com o apoio das várias teorias - buscando mais sobre o homem velho, o professor aposentado, o seu entendimento da vida e da morte - o trabalho se encerra com a sugestão de uma organização alternativa: a organizacionalidade, como um processo que difere do tradicional planejamento rígido de atividades "para" e não "com".

O descontentamento com as instituições, ou quem sabe, com o instituído aprioristicamente, e a curiosidade em saber como se poderia proceder para que, de forma organizada, os homens pudessem ter seus desejos (seu íntimo amortecido) respeitados, ao lado de outras dimensões consideradas nas organizações, levou à realização do estudo. A reflexão retrospectiva sobre os processos organizacionais corriqueiros, ao lado do estudo de novas teorias, fez pensar na possível reparadigmentação. A diferente percepção do mundo se reflete na forma (desde o pensar) de organizar; o processo simultaneamente privilegia a técnica e a cultura, retirando do diálogo entre esses setores diferentes, aparentemente divergentes, mas que se completam, a possibilidade de aceitar as interferências da história, o simples, o singular, o especial e o temporal. A auto-organização substitui a idéia da instituição; o se fazendo, se construindo, se organizando sempre, se reformando, se dissolvendo e fundido, é a tônica; “a dialogia, ordemdesordem-interações-organização" avança sobre a ordem determinada e leis gerais; "a disjunção e o isolamento" são substituídos e recolhe o diverso do "entorno" na sua interferência (cultural). As margens são vivas e na sua dinâmica se transformam e forçam a transformação. Nelas podem estar os indicativos para a solução de problemas até então insolúveis. $O$ inédito pode acontecer. $O$ estranho, o diferente, sendo considerado, na oposição benéfica ao corriqueiro e igual, numa divergência salutar, permite a não igualdade, a homogeneização, e faz surgir o até então desconhecido - $o$ inédito. Permite uma nova relação entre os enfoques (técnico/cultural), mesmo antagônicos, de forma complementar, donde a possibilidade de uma análise "mais rica e mais complexa da realidade".

A reparadigmatização, proposta neste trabalho, prestigia a idéia da complexidade, que, numa atitude de não denegação do "ser" nem da "existência", da "parte" ou do "todo", respeita o individual, que de forma ativa se inclui na pertença geral maior, no todo, no grupo/social; as condições constituem com as semelhanças (variáveis e invarianças), "o caráter de integração processual sincrônico dos opostos"

Cheguei, assim, à paisagem mental do grupo, composta por suas imagens da vida e da morte, com uma nítida tendência à vida, com a negatividade situada apenas nas representações simbólicas, provocadas pela "queda e pelo monstro" elementos constitutivos do teste (Durand, 1988 os elementos constituitivos do Teste A.T. são: Queda, Espada, Refúgio, Monstro Devorador, algo de Cíclico, Personagem, Animal, Água e Fogo). Para reforçar a análise, situei o professor aposentado da pesquisa no seu habitat, no momento da realização da mesma: em Brasília. Para melhor identificação deste homem de Brasília, remeto aos resultados de estudos e pesquisas, efetuados por professores da Universidade de Brasília, sobre a realidade da cidade (Paviani, 1991).

Nessas linha diretora, defendo a proposta de organização que respeita a diferença e a alteridade, que cuida para não incorrer no reforço à determinação, à segurança, à previsibilidade, à dominação, nem tampouco, exagerar na utopia da indeterminação total e transgressão inconseqüentes dos limites, caindo num precoce movimento "libertário" geral, que se acredita, aos poucos, a passos cautelosos, conseguir. É preciso paciência para esperar a metamorfose da "repelente lagarta em borboleta multicor" (Coelho, 1989). Esta organização - organizacionalidade antropolítica - 
se caracteriza pela "indeterminação e incerteza", traços característicos do homem.

Essa ambivalência, diferença e "neotenia neguentrópica" fundamentarão a alternatividade, neste processo organizacional (Carvalho, 1990).

Concluindo, o que pretendi com a pesquisa foi apresentar tão somente novas pistas orientadas para a jornada já iniciadas pelos estudiosos do imaginário, da complexidade e da holonomia, para o entendimento, aceitação e prática de um paradigma diferente do tradicional, positivista, clássico. Trata-se de uma parcela (simbólica) na tarefa somatória transdisciplinar da organizacionalidade reparadigmatizada.

Esta é portanto a contribuição deste trabalho/pesquisa: vetores culturanalíticos, advindos do descortinamento de imagens da vida e da morte de um grupo de professores aposentados, no Distrito Federal, para a criação do possível espaço cultural reparadgmatizado. Pelas limitações de tempo e espaço, apresento, tão somente, estes rápidos recortes da pesquisa. Remeto no entantó à leitura da tese: Imagens da Vida: Vetores Culturanalíticos de um grupo de Idosos e Pistas para a Criação de Um Espaço Cultural (Lahud, 1993).

* Allair Macedo Lahud Loureiro - Professora do Departamento de Planejamento e Administração FE/UnB.

\section{Bibliografia}

ATLAN, Henri. Entre o Cristal e a Fumaça: Ensaio sobre Organizaçăo do Ser Vivo. RJ, Zahar, 1992.

BARROS, Jaão de Deus Vieira, Paisagem Mental e Organizacionalidade na Formaçāo do "ETHOS' Brasileiro: Alguns Aspectos do Imaginário em Gilberto Freire. Tese Mestrado. SP. USP, 1991 (mimeo)

CARVALHO, José Carlos de Paula, Antropologia das organizaçōes Educaçăo: Um Enşaio Holonómico. RJ, Imago, 1990 COELHO, J. Teixeira, Que é Ação Cultural. SP, Primeiros Passos. Editora Brasiliense, 1989.

DURAND, Gilbert. As estruturas Antropológicas do Imaginário. Lisboa, Presença. 1989.

DURAND, Yves, $L$ exploration de $L$ imagiraire, introduction d Ia modeélisation des Universes Mythiques. Paris, L espace. bleu. 1988.

LAHUD LOUREIRO, Altair Macedo Lahud. Imagens da Vida e Morte: Vetores Culturanalíticos de um Grupo de Idosos e Pistas para criação de um Espaço Cultural. Tese de Doutorado. São Paulo, USP, 1993 (mimeo).

MORIN, Edgar. O Enigma do Homem: Para.Uma Nova Antropologia. Traduçăo F.C. Ferro. RJ, Zahar, I979

PAVIANI, Aldo. (org.) A Conquista da Cidade. Movimentos Populares em Brasília. Editora UnB. I991. 